\title{
EL FRACASO DEL PROYECTO DE LEY DE BENEFICIOS EXTRAORDINARIOS \\ DE SANTIAGO ALBA EN 1916: UNA LECTURA POLÍTICA ${ }^{1}$
}

\author{
MIGUEL ÁNGEL MARTORELL LINARES \\ Universidad Complutense de Madrid
}

\section{RESUMEN}

Este artículo aborda dos aspectos importantes en la elaboración de las políticas fiscales durante la Restauración: la posición central del Parlamento en la toma de decisiones político-fiscales y las relaciones entre los partidos con representación parlamentaria y los grupos de presión. En 1916 el ministro de Hacienda Santiago Alba intentó incorporar al sistema tributario español un impuesto sobre los beneficios extraordinarios derivados, adoptado ya por la mayoría de los países beligerantes en la Primera Guerra Mundial y por algunos neutrales. El Proyecto de ley sucumbió en el Congreso de los Diputados debido a la obstrucción de un nutrido conjunto de diputados liderado por la Lliga Regionalista.

Algunos historiadores han explicado la derrota del proyecto de Alba por la fuerza y la eficacia de los grupos de presión económicos y por la subordinación de los partidos políticos representados en el Parlamento a sus intereses. Este artículo discrepa de dicha tesis. Intenta demostrar que la actitud de la Lliga Regionalista vino determinada por razones estrictamente políticas. Su objetivo era debilitar el sistema político de la Restauración, considerado como una traba para el desarnollo de la autonomía catalana. En su lucha contra Alba, la Lliga recibió el apoyo de varios diputados que, sin el respaldo de sus partidos, actuaron en defensa de los intereses económicos afectados por el proyecto en sus distritos.

${ }^{1}$ Este trabajo es parte de las investigaciones realizadas para la elaboración de una tesis doctoral dirigida por Francisco Comín titulada El Parlamento y las reformas tributarias en España, 1900-1923. Los comentarios de Mercedes Cabrera han enriquecido considerablemente el texto. Asimismo, agradezco las observaciones de los comentaristas anónimos de la Revista de Historia Económica. 


\section{ABSTRACT}

This article deals with two important matters of the making of fiscal policy during the Spanish Restoration: the central position of the Parliament in the making of fiscal policy, and the relations between the parliamentary parties and the pressure groups. In the year 1916, the Spanish Chancellor of the Exchequer, the liberal Santiago Alba, tried to incorporate the War Profits Tax to the Spanish tax system, adopted by the majority of the countries at the First World War and by some neutral countries. The bill failed in the Parliament because of the obstruction of a large group of MPs leaded by the Lliga Regionalista, a Catalonian nationalist party.

It is said by some historians that the failure of Alba's bill was due to the strength and the efficiency of the pressure groups and by the subordination of the parliamentary parties of their interests. This article disagrees with this thesis. It tries to prove that the attitude of the Lliga Regionalista was instigated by strictly political reasons. Its objetive was to weaken the political system of Spanish Restoration. The Lliga considered that this political system was an obstacle for the development of the Catalonian home rule. In its struggle against Santiago Alba, the Lliga was supported by several MPs. They fought the bill in defence of the predominant economic interests in their electoral districts, withouth the support of their parties.

\section{INTRODUCCIÓN}

Este artículo aborda dos aspectos fundamentales en la elaboración de las políticas tributarias durante la Restauración: el lugar central ocupado por el Parlamento en la toma de decisiones político-fiscales y las relaciones entre los partidos con representación parlamentaria y los grupos de presión económicos. El proceso político que condujo al fracaso del Proyecto de ley de beneficios extraordinarios de Santiago Alba en 1916 permite realizar una aproximación a ambos problemas. Alba quiso incorporar a la legislación española un modelo de tributo que, a mediados de 1916, había sido adoptado por la práctica totalidad de los países beligerantes en la Primera Guerra Mundial y por algunos Estados neutrales próximos a los campos de batalla. La guerra acentuaba la expansión del déficit de la Hacienda española, que en 1915 se había cerrado en 811 millones. La escasa elasticidad del sistema tributario impedía que el Estado se beneficiara del impulso conferido por el conflicto bélico a determinadas actividades económicas. Había que buscar nuevas fuentes de ingresos. De ahí la importancia del Proyecto, cuyos rendimientos, para su primer año, se estimaban en 30 millones. Sin embargo, la difícil situación de la Hacienda 
no fue motivo suficiente para que los partidos representados en el Parlamento apoyaran la iniciativa de Alba. Los diputados de la Lliga Regionalista emprendieron una dura campaña de obstrucción en la que fueron secundados por los representantes de la provincia de Vizcaya y otros diputados aislados. El 12 de julio, diez después de iniciarse los debates parlamentarios, bloqueado el Proyecto, el Gobierno cerraba las Cortes ${ }^{2}$.

En todo régimen parlamentario, las Cámaras legislativas ocupan el lugar central en el proceso de toma de decisiones. La afirmación podría parecer obvia, pero a juzgar por la escasa atención dedicada por la historiografía, tanto política como económica, al Parlamento de la Restauración, no lo es tanto. Este texto reivindica el interés de los estudios parlamentarios en los trabajos sobre la historia de las políticas económicas. Uno de los campos en los que la posición central de las Cortes resulta más evidente es el de la elaboración de las políticas tributarias. El artículo 42 de la Constitución de 1876 estipulaba que la creación de nuevos impuestos o la modificación de los ya existentes era competencia exclusiva del Parlamento. Correspondía a las Cortes ratificar, rectificar o rechazar los proyectos de reforma tributaria elaborados por los gobiernos. El éxito de éstos dependía de su habilidad para negociar con los partidos que integraban la oposición o de su capacidad para imponerles su criterio. Diputados y senadores controlaban el acceso al ámbito de toma de decisiones, ejerciendo una suerte de gatekeeping. Los grupos de presión interesados en frenar una iniciativa de reforma tributaria necesitaban el apoyo de un partido o, al menos, el de un grupo informal de parlamentarios ${ }^{3}$.

Esta última idea enlaza con el segundo problema que se afronta en este trabajo: las relaciones entre partidos y grupos de presión económicos en la Restauración. Según la interpretación elaborada por García Delgado,

2 Sobre el Proyecto de ley de beneficios extraordinarios véase García Delgado, Muñoz y Roldán (1973), pp. 255-322. Una visión global de la obra de Alba en el Ministerio de Hacienda, enmarcada en su contexto político, en Cabrera, Comín y García Delgado (1989). Véase también García López (1984). Entre las biografías de Alba pueden consultarse la clásica de García Venero (1963) y la posterior de Marín Arce (1991). Valoraciones contemporáneas sobre el Proyecto de beneficios extraordinarios y el conjunto de la obra de Alba, en Ríu (1916), Ceballos Teresí (1916) y Casais (1917). La crítica conservadora al Proyecto, en Canals (1916). Duros juicios sobre la obra de Alba, en Rahola (1917) y Marichalar (1917).

${ }_{3}^{3}$ Sobre la función de gatekeeping en las relaciones entre partidos y grupos de presión, véase Morlino (1992), pp. 60 y ss. Este texto se inscribe en el Proyecto «Parlamento, sisterna de partidos y representación de intereses 1914-1923», dirigido por Mercedes Cabrera y financiado por DGICYT. Algunos avances de la investigación pueden verse en Arranz, Cabrera (1995, 1996), Cabrera (1995, 1996), Martorell Linares (1996a, 1996b, 1997), Rey, Moreno (1996). 
Roldán y Muñoz en 1973, la obstrucción parlamentaria al Proyecto de ley de beneficios extraordinarios fue fruto de la «amplia capacidad de maniobra de que hac(ía) gala el capitalismo español». Los diputados actuaron impulsados por la movilización de las organizaciones patronales, que tuvo su epicentro en la Asamblea celebrada en el Hotel Palace el 28 de junio de 1916, a la que acudieron representantes de todos los sectores de la producción afectados por el Proyecto y políticos de todo el arco parlamentario. Cambó y los diputados de la Lliga Regionalista encabezaron la obstrucción, secundada por el resto de las grupos representados en el Congreso, excepción hecha de los republicanos. Desde que García Delgado, Roldán y Muñoz analizaron el fracaso de la obra de Alba mucho se ha escrito sobre las relaciones entre partidos políticos y grupos de presión durante la Restauración. Mientras que algunos autores han cuestionado la capacidad de estos últimos para influir en el proceso de toma de decisiones político-económicas, otros, por el contrario, han insistido en la incidencia de los lobbies en las agendas políticas. Una de las aportaciones más interesantes de los últimos años tiende a buscar una cierta síntesis entre estas dos posiciones encontradas. Fernando del Rey considera que para definir los vínculos entre los políticos de la Restauración y los grupos de presión económicos lo más correcto es hablar de una «instrumentación recíproca, parcial y limitada». Políticos y grupos de presión se utilizaron mutuamente, aunque esta relación no supuso una pérdida de la autonomía relativa de los primeros respecto a los segundos ${ }^{4}$.

El planteamiento de Fernando del Rey da cobertura a algunas de las propuestas que se barajan en este artículo para explicar el fracaso del Proyecto de ley de beneficios extraordinarios de Santiago Alba. La primera atañe a la actitud de la Lliga Regionalista. Según se argumenta en el texto, no fueron los vínculos con los grupos de presión los que indujeron al partido de Cambó a bloquear el Proyecto. Por el contrario, las relaciones de los regionalistas con las organizaciones patronales catalanas atravesaban un punto de máxima tensión en estas fechas. La Lliga optó por la obstrucción siguiendo una estrategia partidista, de carácter netamente político, dirigida a romper o debilitar el sistema del turno de partidos, percibido como una

${ }^{4}$ García Delgado, Muñoz y Roldán (1973), pp. 255-322. La cita corresponde a la página 300. Entre quienes cuestionan la capacidad de las organizaciones patronales para incidir en la agenda política figuran, por ejemplo, Varela Ortega (1977) y Arana (1988). Entre los defensores de la eficacia de la acción de los lobbies destacan, entre otros, Valdaliso (1990), Escudero (1990, 1994). Rey toma el concepto de Pérez Díaz. Véase Rey Reguillo (1992), pp. 685 y ss. La cita es de la página 694. 
traba al desarrollo de mayores cuotas de autogobierno para Cataluña. Esta idea ya fue esbozada hace algunos años por Mercedes Cabrera. La segunda aborda las razones que impulsaron al resto de los diputados que también participaron en la obstrucción, entre los que destacó la representación parlamentaria de la provincia de Vizcaya en el Congreso. Su actitud se pretende encuadrar en un modelo común en la práctica política de la Restauración: la representación de intereses económicos locales en el Parlamento. A excepción de los parlamentarios de la Lliga, los diputados que participaron en la obstrucción actuaban como representantes de los principales productores de los distritos por los que eran elegidos. Por último, el artículo también pretende redefinir la actitud de los distintos grupos parlamentarios ante el Proyecto. En el libro de García Delgado, Roldán y Muñoz todos los partidos aparecen implicados en la obstrucción salvo los republicanos, que apoyaron a Santiago Alba. Este texto sostiene que sólo la Lliga Regionalista adoptó la obstrucción como estrategia de partido, de la cual el Partido Conservador y sus disidencias maurista y ciervista se desmarcaron expresamente. En el lado contrario, los republicanos adoptaron una actitud ambigua y regatearon su apoyo a Santiago Alba ${ }^{5}$.

$\mathrm{El}$ artículo se divide en ocho secciones, cuatro de ellas dedicadas a introducción, conclusiones, apéndices y bibliografía. La segunda sección trata sobre el contenido del Proyecto, su relación con otras iniciativas contemporáneas similares y con el resto del programa económico de Alba. La tercera ofrece una breve guía sobre su tramitación parlamentaria. La cuarta analiza las razones que provocaron la obstrucción de los diputados de la Lliga Regionalista y de la provincia de Vizcaya. La quinta revisa la actitud del resto de los grupos parlamentarios, desde las minorías conservadora y republicana hasta la mayoría liberal.

\section{EL PROYECTO. CONTENIDOS Y REFERENCIAS}

La necesidad de buscar nuevos recursos para financiar el esfuerzo bélico condujo a la mayoría de los países beligerantes en la Primera Guerra Mundial a crear impuestos sobre las actividades comerciales, industriales y financieras que, favorecidas por la dinámica de la guerra, generaban beneficios superiores a los considerados normales en tiempo de paz. Para

${ }^{5}$ Véase Cabrera, Comín, García Delgado (1989), pp. 104 y ss. Sobre la representación de intereses económicos locales en el Parlamento véase Martorell Linares (1996a, 1996b). García Delgado, Muñoz y Roldán (1973), pp. 255-322. 
marcar la diferencia entre ganancias ordinarias y extraordinarias las leyes que regulaban dichos impuestos comparaban los beneficios obtenidos en los años de la guerra con un promedio de los reconocidos por las empresas en los últimos años de paz, elaborado a partir de las declaraciones efectuadas en los impuestos sobre el capital mobiliario o sobre la renta. Asimismo, en casi todos los casos el período contable se iniciaba en el verano de 1914 . Se trataba, por tanto, de tributos de carácter retroactivo, ya que en su mayoría fueron aprobados por los respectivos gobiernos y parlamentos a partir de la segunda mitad de 1915. Italia incorporó el impuesto sobre los beneficios extraordinarios a su legislación el 21 de noviembre de ese mismo año. Inglaterra y Alemania, el 21 y el 24 de diciembre, respectivamente. A lo largo de 1916 se les unieron Francia, Austria-Hungría y Rusia. Países neutrales como Dinamarca, Suecia o Suiza también crearon impuestos similares. Sus Haciendas, afectadas como las de otros países europeos por la quiebra del comercio internacional y la distorsión de los mercados financieros, tenían que hacer frente, además, al costo adicional derivado de la movilización de los reservistas, en previsión de que la guerra se extendiera hacia sus fronteras ${ }^{6}$.

A partir de 1915, tras una primera fase de desconcierto y desorganización, la economía española inició una etapa de fuerte desarrollo. Aumentaron las exportaciones de determinados productos, a la par que el bloqueo del comercio internacional promovió la sustitución de las importaciones por productos de fabricación nacional. Fue un proceso desigual, ya que mientras algunos sectores de la economía crecieron, otros atravesaron una fuerte recesión. Entre los primeros cabe destacar a la industria siderometalúrgica, la minería o al sector naviero, mientras que la exportación de cítricos o la construcción pertenecen al segundo grupo. Debido a su escasa elasticidad, el sistema tributario fue incapaz de aprovechar el nuevo impulso de la economía. Por el contrario, el déficit creció. La mayor demanda exterior de algunos productos provocó el desabastecimiento del mercado interior y los gobiernos se vieron obligados a comprar y redistribuir alimentos básicos a bajo precio para combatir las crisis de subsistencias. También aumentó el número de obras públicas para

${ }^{6}$ Acerca de los impuestos sobre los beneficios extraordinarios en Europa hay interesantes trabajos en la prensa española de la época. Véase José María González, «Los beneficios de la guerra y la tributación fiscal», España, 25 de mayo de 1916, núms. 70, 71 y 72. También X. X. X., «El Impuesto sobre los beneficios ocasionados por la guerra», Revista Nacional de Economia, núm. 1, abril-mayo 1916, pp. 108-123. Una valoración global sobre los proyectos europeos en García Delgado, Roldán y Muñoz (1973), pp. 230 y ss. 
rebajar el alto índice de paro en las regiones más perjudicadas. Por otra parte, los ingresos por la renta de Aduanas disminuyeron al caer las importaciones. El déficit, que en 1913 era de 71 millones, en 1915 había alcanzado los 811. Para atajar el desequilibrio presupuestario Gabino Bugallal, ministro de Hacienda conservador en este último año, estudió la posibilidad de crear «un Impuesto sobre las magnas ganancias obtenidas con motivo de la guerra», pero desechó la idea ante el temor a que «el público en general se mostrara hostil y aun agresivo» ${ }^{7}$.

Santiago Alba, que ocupó poco después la cartera de Hacienda en el gobierno liberal del conde de Romanones, sí optó por instaurar un tributo sobre los beneficios extraordinarios derivados de la guerra. Formaba parte de un complejo programa de política económica dirigido a reforzar los ingresos del Estado, canalizar el impulso de la economía y, mediante una política de inversiones en infraestructura, paliar el problema del paro, que afectaba a amplios sectores de la población. El programa de Alba constaba de un Proyecto de Presupuesto ordinario para 1917, un Proyecto de Presupuesto Extraordinario o de Reconstitución Nacional, que contemplaba importantes inversiones en infraestructura para el decenio 1917-1927 y una veintena de Proyectos de ley que abordaban todas las áreas de la actividad económica. Alba pretendía reorganizar la Administración de Hacienda, fomentar el desarrollo de la economía nacional y resolver los problemas de orden financiero generados por la guerra. No obstante, la parte más interesante de su programa económico eran los proyectos de reforma tributaria. Además de modificar gran parte de los impuestos ya existentes, el ministro de Hacienda proponía la creación de nuevas figuras tributarias. Las más importantes eran la contribución sobre los beneficios extraordinarios, el monopolio sobre la venta de alcoholes y el impuesto sobre el aumento del valor de la propiedad inmueble. De los dos primeros esperaba obtener en 1917, respectivamente, 30 y 34,5 millones de pesetas, más del 50 por 100 de los ingresos previstos en toda su reforma tributaria ${ }^{8}$.

La proyectada contribución directa sobre los beneficios extraordinarios afectaba a todo tipo de compañías, sociedades y negocios de particulares,

${ }^{7}$ Los datos sobre el déficit, en Comín (1988), cuadro 20b, pp. 654-5. La iniciativa de Bugallal, en El Imparcial, 3 de octubre de 1915. Sus declaraciones, en Diario de Sesiones de las Cortes-Congreso de los Diputados (DSC-CD), 11 de julio de 1916, núm. 49, p. 1305. Una fuente de primera mano sobre la incidencia del segundo año de guerra sobre la economía española, en Instituto de Reformas Sociales (1916).

${ }^{8}$ Los datos sobre los ingresos previstos proceden de DSC-CD, 30 de septiembre de 1916, núm. 56, ap. 1. La relación de proyectos del programa económico, en Alba (1916, 1919). 
industriales o mercantiles radicados en España, fueran nacionales o extranjeros. Al igual que sus referentes europeos, actuaba con carácter retroactivo, ya que se remitía a las actividades emprendidas a partir del 1 de enero de 1915. Para estipular qué se estimaba como beneficio extraordinario el Proyecto seguía dos vías. En las compañías creadas durante la guerra se entendía como tal el que superara el 7 por 100 del capital anual. En las existentes con anterioridad se hallaba un promedio de los beneficios declarados en la Contribución de Utilidades durante los dos ejercicios previos al 1 de agosto de 1914. Este último procedimiento de valoración era igual al contemplado en la Ley que regulaba el Impuesto sobre los beneficios extraordinarios en Italia. Los tipos de imposición estaban sometidos a una escala progresiva que oscilaba desde el 25 por 100 sobre la fracción de las ganancias que, excediendo del beneficio normal, no sobrepasaran el 20 por 100 del capital empleado, hasta el 40 por 100 sobre la fracción de beneficios que excediera del 100 por 100 del capital empleado. La vigencia del Impuesto era imprecisa, pues se sometía «al curso de las eventualidades que determin(ara)n los beneficios extraordinarios» ${ }^{9}$.

Para garantizar el cumplimiento de los deberes tributarios el Proyecto incluía una dura serie de disposiciones contra el fraude y la ocultación, que llevaron a las organizaciones patronales a acusar a Alba de dañar el derecho a la privacidad inherente a las actividades empresariales. Sociedades y particulares debían presentar declaraciones de beneficios, bajo pena de multas de hasta un 20 por 100 de la cantidad omitida. La Administración podía examinar libros, facturas, correspondencia y demás documentos de sociedades o particulares. La falsedad en la declaración se sometía al artículo 315 del Código Penal. La resistencia a los funcionarios se castigaba con multas de 500 a 5.000 pesetas. Las críticas más aceradas se dirigieron contra el artículo 16, que proponía que los administradores legales de las sociedades fueran responsables subsidiarios del pago del tributo. Otros argumentos de las organizaciones patronales contra el Impuesto señalaban las dificultades para establecer una frontera que delimitara qué beneficios eran ordinarios y cuáles extraordinarios. Abundaban también las condenas a la retroactividad y las consideraciones sobre la incapacidad de la Administración fiscal española para poner en práctica una contribución tan compleja ${ }^{10}$.

${ }^{9}$ El texto del Proyecto, en DSC-CD, 3 de junio de 1916, núm. 19, ap. 4. ${ }^{\circ}$

${ }^{10}$ Las protestas de las organizaciones patronales pueden verse en los informes remitidos a la Comisión de Presupuestos del Congreso durante la información abierta sobre el Proyecto. 


\section{BREVE GUÍA SOBRE LA TRAMITACIÓN PARLAMENTARIA DEL PROYECTO}

El Proyecto de ley de beneficios extraordinarios se tramitó en las Cortes surgidas de las elecciones de abril de 1916, organizadas por el gobierno liberal del conde de Romanones, con Santiago Alba en el Ministerio de la Gobernación. La composición del Congreso muestra una realidad política muy alejada de la tradicional imagen de plácido dominio bipartidista asociada a la Restauración. La mayoría parlamentaria liberal, con 224 diputados sobre un total de 415, era fruto de la coalición de los grupos dirigidos por García Prieto y Romanones. Los 111 escaños conservadores se distribuían entre los cuatro diputados de Juan de la Cierva, los 16 de Antonio Maura y los 91 diputados del Partido Conservador de Eduardo Dato. Entre los republicanos había tres partidos. La Conjunción Republicano-Socialista contaba con 14 diputados, entre ellos el socialista Pablo Iglesias. El Partido Reformista de Melquiades Álvarez, de carácter más moderado, tenía 13. Los republicanos radicales de Alejandro Lerroux sólo eran cuatro. Completaban el arco parlamentario la Lliga Regionalista de Cataluña, con 13 diputados dirigidos por Francisco Cambó, y los grupos de la extrema derecha -integristas, jaimistas y tradicionalistas-, que sumaban 10 escaños. Los demás diputados eran independientes o de difícil adscripción ${ }^{11}$.

El 3 de junio de 1916, dos meses después de llegar al Ministerio de Hacienda, Santiago Alba presentó en el Congreso el Proyecto de ley de beneficios extraordinarios. A los pocos días, una Comisión especial integrada por siete diputados liberales comenzaba a estudiar el texto para emitir el dictamen que sería debatido en la Cámara Baja. Al crear dicha Comisión, el Gobierno quebrantó una norma no escrita de la práctica parlamentaria de la Restauración por la cual los proyectos de reforma tributaria se debían someter al análisis de la Comisión de Presupuestos, donde tenían representación todas las minorías. Con esta decisión, Alba intentaba ganar tiempo esquivando la fiscalización de la oposición y evitando una proliferación de votos particulares que prolongara en exceso los debates. Por otra parte, también perdía una buena oportunidad para

Véase Archivo del Congreso de los Diputados (ACD), Sección General, leg. 432-1. Un resumen del contenido de los informes, en García Delgado, Roldán y Muñoz (1973), pp. 273 y ss.

"La fuente principal es la base de datos elaborada por Mercedes Cabrera, Luis Arranz y Fernando del Rey sobre personal parlamentario entre 1914 y 1923. 
alcanzar un mayor consenso con las minorías sobre el contenido del Proyecto. La Comisión abrió un período de información escrita. Recibió 71 informes de protesta, firmados por grupos patronales y entidades comerciales, industriales y financieras. El día 17 publicó su dictamen. El texto respetaba el espíritu del Proyecto e incluía pequeñas modificaciones entre las que destacaban una pequeña reducción de los tipos impositivos y el mejor trato dado a los beneficios extraordinarios reinvertidos en los negocios ${ }^{12}$.

El 21 de junio de 1916, mediante un Real Decreto, Alba puso en vigor el artículo 16 del dictamen, que convertía a los administradores de las empresas en responsables subsidiarios de las cantidades exigibles por la contribución. Respondía así al envite de algunas compañías navieras de Vizcaya que, para impedir las liquidaciones con carácter retroactivo, habían amenazado con su disolución y posterior restablecimiento con distinto nombre si se aprobaba el Proyecto. La disposición generó una agria polémica sobre las competencias respectivas del Legislativo y el Ejecutivo. El 24 de junio el conservador Gabino Bugallal acusó al Gobierno de vulnerar la Constitución al publicar por Decreto parte de un texto sometido a la discusión de las Cámaras, ejerciendo la potestad legislativa por encima del Parlamento. Compartieron su argumento Maura, Cambó, los republicanos conjuncionista y reformista Nougués y Melquiades Álvarez, el integrista Llosas y el jaimista Senante. Sólo apoyaron al Gobierno los republicanos radical e independiente Lerroux y Rodés. El debate finalizó con una moción de confianza que Romanones superó por la abstención de las minorías, ya que sólo fue respaldada por 152 de los 224 diputados que integraban la mayoría liberal. Esa misma semana, el 28 de junio, se celebró en el Hotel Palace de Madrid una concentración de industriales, comerciantes y financieros afectados por el Proyecto, procedentes de toda España. Aunque fue un acto extraparlamentario, a la convocatoria acudieron más de una veintena de diputados. La lista de participantes anunciaba el rumbo que adoptarían los debates. Estuvieron presentes los dos núcleos que lideraron la obstrucción: casi la mitad de los diputados de la Lliga y la totalidad de la representación vizcaína en el Congreso.

12 Protestas de conservadores y republicanos reformistas sobre la sustracción del dictamen a la Comisión de Presupuestos, en La Época, 7 de junio de 1916, y DSC-CD, 11 de julio de 1916, núm. 49, p. 1305. Un resumen del contenido de los informes remitidos a la Comisión, en García Delgado, Roldán y Muñoz (1973), pp. 273 y ss. Los informes, en Archivo del Congreso de los Diputados (ACD), Sección General, leg. 432-1. El dictamen, en $D S C-C D, 17$ de junio, núm. 31 , ap. $2^{\circ}$, p. 1. 
También asistieron cuatro diputados liberales. Dos de ellos, los catalanes Sala y Ballbé, no habían votado dos días antes la moción de apoyo al Gobierno ${ }^{13}$.

La discusión de los turnos contra la totalidad, entre el 3 y el 6 de julio, mostró uno de los rasgos que caracterizaron los debates: el contraste entre los diputados que participaron en ellos como delegados de sus partidos y los que actuaron defendiendo los intereses económicos perjudicados por el Proyecto en sus distritos. Juan Ventosa y Mariano Ordóñez, dos de los cuatro primeros diputados que intervinieron, atacaron el Proyecto como miembros de la Lliga Regionalista y el Partido Conservador. Por el contrario, el conservador cántabro Juan José Ruano y el jaimista vizcaíno Joaquín Ampuero hablaron, respectivamente, como «diputado a Cortes por Santander» y en representación de los diputados de Vizcaya, «una región —en sus propias palabras- directamente interesada en esta cuestión» ${ }^{14}$.

El 6 de julio, con la discusión del articulado, se inició la verdadera batalla entre el Gobierno y los diputados de la Lliga Regionalista, a los que se unieron los parlamentarios de la provincia de Vizcaya, también interesados en bloquear el trámite del Proyecto mediante la obstrucción. Los rebeldes utilizaron todos los recursos permitidos por el Reglamento del Congreso: discursos interminables, votaciones nominales, numerosas intervenciones por alusiones y redacción de proposiciones incidentales. No obstante, la argucia más eficaz fue la presentación masiva de enmiendas. Cada artículo podía recibir un número ilimitado de éstas. El día 5 de julio la Comisión había aceptado 70; al día siguiente, eran 89; el día 8, sobrepasaban las 120; al final, llegaron a 140. Para valorar la eficacia de esta práctica téngase en cuenta que no existía un límite de tiempo para la duración de los discursos en defensa de las enmiendas, que la Comisión debía rebatirlos y que el promotor tenía derecho a réplica. Si algún diputado era aludido en alguno de estos trámites, podía intervenir en el debate. Considérese, por último, que las sesiones normales duraban cuatro horas, dos de las cuales se dedicaban a preguntas e interpelaciones al Gobierno. Para ganar tiempo, Romanones negoció con las minorías la ampliación

${ }^{13}$ Bugallal, en $D S C-C D, 24$ de junio, núm. 36, pp. 800 y ss. La Asamblea del Hotel Palace, el contenido de los discursos allí celebrados y los acuerdos adoptados, en García Delgado, Muñoz y Roldán (1973), pp. 292 y ss. Sobre los diputados asistentes a la Asamblea véase La Época, 28 de junio de 1916.

14 Ruano y Ampuero, en DSC-CD, 3 de julio de 1916, núm. 42, p. 1060, y DSC-CD, 5 de julio de 1916 , núm. 44 , p. 1132 , respectivamente. 
en otras dos horas de la duración de las sesiones. Los regionalistas rechazaron la iniciativa alegando que, dada su oposición al Proyecto, «no era lógico que dieran facilidades para su aprobación». El resto de los grupos, interesados en desmarcarse de la estrategia obstruccionista de la Lliga, apoyaron la petición del Gobierno y las sesiones se prorrogaron durante dos horas. Aun así, una sesión parlamentaria podía irse en el debate de una o dos enmiendas ${ }^{15}$.

Entre el 6 y el 10 de julio las sesiones se consumieron en el debate de nueve enmiendas al artículo primero. Cuando el día 10 comenzó la discusión del turno contra la totalidad de dicho artículo el Gobierno ya había perdido el control sobre la situación. Sólo entonces Alba intentó pactar el contenido del Proyecto con las oposiciones. El 11 de julio leyó una propuesta de transacción que asumía el contenido de varias enmiendas. No obstante, se mantuvo inflexible frente a la principal demanda de las minorías conservadoras: la eliminación del principio de retroactividad. Alegó que si éste se suprimía, «casi» desaparecería «la eficacia del tributo». Rechazada la oferta por todos los grupos a excepción de los republicanos reformistas, Alba no modificó el dictamen. El día 12 el artículo primero fue aprobado por 141 votos -liberales, reformistas y varios republicanos conjuncionistas- contra 47 -conservadores, mauristas, ciervistas, regionalistas, jaimistas e integristas-. En términos estratégicos, la victoria del Gobierno fue más aparente que real. El texto constaba de 20 artículos. El trámite del primero había ocupado cinco días, y si la obstrucción proseguía al mismo ritmo, los debates se adentrarían en el otoño. Ese mismo día, tras la votación, se interrumpió la discusión del Proyecto, lo que motivó que adquiriera «gran consistencia el rumor de que las Cortes suspenderían las sesiones». Un fuerte incremento de la conflictividad social, debido a una huelga de ferroviarios, permitió zanjar un conflicto que no tenía fácil salida. El 13 de julio Romanones declaró el estado de guerra, suspendió las garantías constitucionales y clausuró las Cortes. Alba se opuso a esta decisión, pero no pudo evitarla ${ }^{16}$.

${ }^{15}$ Sobre la obstrucción en la Restauración véase Posada (s.f.). Para una visión más general, Pérez-Serrano Jáuregui (1983). La progresión en la llegada de enmiendas a la Comisión, en $A B C, 5-8$ de julio de 1916. La cita regionalista es de Juan Ventosa, La Tribuna, 6 de julio de 1916 .

${ }^{16}$ La cita de Alba, en DSC-CD, 11 de julio de 1916, núm. 49, p. 1319. El contenido de la propuesta aparece resumido en $A B C, 12$ de julio de 1916. La segunda cita es de $A B C, 13$ de julio de 1916. La oposición de Alba a la suspensión de las sesiones, en Pabón (1952), p. 462. 
El 2 de octubre, pocos días después de iniciarse la temporada parlamentaria de otoño, Cambó hizo una oferta al Gobierno: aceptaría la tramitación de algunos proyectos del programa económico de Alba si éste postergaba la discusión de las reformas tributarias. Alegó, además, que los debates sobre el Proyecto de ley de beneficios extraordinarios no podían proseguir en tanto no se incorporaran al texto del dictamen los cambios ofrecidos a la oposición el 11 de julio. Las minorías respaldaron sus argumentos y Alba tuvo que ceder. A instancias del Gobierno, la Comisión retiró el grueso del dictamen para modificarlo, pero dejó en la Mesa del Congreso sus dos primeros artículos. El ministro de Hacienda temarcaba así su voluntad de no abandonar el Proyecto. El gesto fue lo suficientemente explícito como para que los regionalistas prosiguieran redactando enmiendas contra el artículo segundo. El propio Cambó manifestó que «por cada una que se desech(ara), se presentar(ía)n dos nuevas». En los meses de octubre, noviembre y diciembre Alba intentó, sin éxito, alcanzar un acuerdo con la patronal vizcaína. La publicación del nuevo dictamen el 20 de diciembre, sin apenas cambios respecto a la propuesta del 11 de julio, reflejó el fracaso de las negociaciones. En enero de 1917 los empresarios vascos notificaban al subsecretario de Hacienda, Joaquín Chapaprieta, «la inutilidad de reanudar las conferencias» ${ }^{17}$.

Por estas fechas el Gobierno liberal pasaba por una situación muy comprometida. Día a día aumentaba la presión de las grandes potencias para una mayor implicación española en la Gran Guerra. Romanones, acosado por la prensa germanófila, había dimitido a principios de mes, aunque el rey le ratificó en su puesto. En estas condiciones, el Gobierno llevó a las Cortes un Proyecto de ley que le autorizaba a recurrir al endeudamiento para financiar el gasto estatal durante un largo interregno parlamentario. Cuando el 10 de febrero de 1917 el republicano Hilario Ayuso reclamó en el Congreso la reanudación de los debates sobre el Proyecto de beneficios extraordinarios, Alba alegó dos razones para rechazar su propuesta. En primer lugar, el Proyecto de ley de autorizaciones se apoyaba en la «transacción con la opinión de todos los sectores de la Cámara». En otras palabras, Alba renunciaba a gravar los beneficios extraordinarios a cambio de que la Lliga no obstruyera el Proyecto de

${ }^{17}$ Cambó, DSC-CD, 2 de octubre de 1916, núm. 56, p. 1480. La cita de Cambó es del diario El País, 5 de octubre de 1916. El nuevo dictamen, en DSC-CD, 20 de diciembre de 1916, núm. 121 , ap. $7 .^{\circ}$ Las negociaciones de Chapaprieta con los empresarios vascos pueden seguirse en el Archivo Santiago Alba (AA), legs. 3/39-1, 3/39-2, 3/39-3. 
autorizaciones. El segundo argumento estaba relacionado con el sector naval y las nuevas condiciones impuestas por la guerra al tráfico internacional de mercancías. El Gobierno planeaba medidas excepcionales encaminadas a «mantener la navegación nacional», dificultada por la guerra submarina. En esta nueva coyuntura era imposible «complicar la situación de las cosas con la implantación de un nuevo régimen fiscal». Pese a todo, Alba insistía: «no renuncio al Proyecto de ley de beneficios extraordinarios», sobre el cual, aseguraba, «en su día», recaería «la discusión y el voto del Parlamento». No dejaba de ser una afirmación retórica. Pocos días después se celebró la última reunión de las Cortes liberales ${ }^{18}$.

\section{LAS RAZONES DE LA OBSTRUCCIÓN. ESTRATEGIAS DE PARTIDO Y REPRESENTACIÓN DE INTERESES ECONÓMICOS EN EL PARLAMENTO}

En la obstrucción al Proyecto de ley de beneficios extraordinarios participaron de forma destacada los diputados de la Lliga Regionalista y los representantes parlamentarios de la provincia de Vizcaya. De los dieciséis diputados que suscribieron un mayor número de enmiendas, tal y como reflejan los cuadros 1 y 2 , seis eran regionalistas y cinco vizcaínos. Ambos grupos, en estrecha colaboración, tomaron la iniciativa en la redacción del 51 por 100 de las enmiendas. Sin embargo, tal y como se expone en las siguientes páginas, las razones que les impulsaron a bloquear el Proyecto eran de distinta naturaleza.

\subsection{La Lliga Regionalista y la obstrucción. Una estrategia de partido}

La Lliga Regionalista justificó su campaña de obstrucción a la contribución sobre los beneficios extraordinarios en la defensa de los intereses generales de la industria y el comercio. Mientras que los diputados vizcaínos alegaron el amparo de las actividades económicas predominantes en sus distritos, los regionalistas, por el contrario, no intervinieron en defensa de los empresarios catalanes, pese a que su condición de partido de ámbito local podía disculpar este argumento y pese a que algunos de sus diputados ocupaban cargos de responsabilidad en organizaciones patronales de Cataluña. Éste era el caso, por ejemplo, de Luis Ferrer i

18 Santiago Alba, DSC-CD, 10 de febrero de 1917, núm. 12, p. 329. 
Vidal, presidente de la Cámara Oficial de Industria de Barcelona. Es difícil saber qué razones impulsaron a los regionalistas a obviar la defensa de las industrias catalanas. Quizá fuera el intento de dotar de un mayor alcance a su discurso, rehuyendo la crítica de un excesivo localismo. Quizá fuera debido a que, por estas fechas la relación de la Lliga con las organizaciones patronales catalanas atravesaba un período de extrema tensión, que casi concluyó en su ruptura durante el verano de 1916. En todo caso, este discurso responde a una estrategia de partido mucho más elaborada que la esgrimida por el resto de los diputados que también participaron en la obstrucción ${ }^{19}$.

Durante los debates surgidos a raíz del Real Decreto del 21 de junio Cambó avanzó las principales críticas regionalistas contra el Proyecto: traducía textos ajenos a la realidad nacional; la retroactividad atentaba contra la lógica de la producción económica; la contribución era ineficaz con una Administración inoperante como la española y se regía por un doble baremo, al someter a industriales y comerciantes pero no a los propietarios agrícolas y ganaderos. Exceptuando este último, el resto de los argumentos fueron también defendidos por conservadores, mauristas o ciervistas. Sin embargo, estos grupos, aunque combatieron el Proyecto, no optaron por la obstrucción. ¿Qué motivó la diferencia entre ambas actitudes? ${ }^{20}$.

Tres propuestas historiográficas han explicado la virulenta actitud de la Lliga frente a la política económica de Santiago Alba. La primera, perfilada por Jesús Pabón en los años cincuenta, hace especial hincapié en la enemistad personal entre Alba y Cambó como factor condicionante de las relaciones entre los grupos que ambos lideraban. Esta argumentación fue categóricamente descartada por García Delgado, Roldán y Muñoz. No obstante, la elocuente valoración de Cambó sobre el paso de Alba por e! Ministerio de Hacienda deja pocas dudas sobre el bajo concepto que tenía del político vallisoletano: «Alba perdió la batalla de $1916-17 \ldots$ por exceso de pretensiones, por falta de coraje y por carencia de prestigio...

19 Los diputados regionalistas rehuyeron la defensa expresa de los intereses económicos catalanes. Bertrán y Musitu enumeró las industrias que debían quedar excluidas: mencionó tres predominantes en la cornisa cantábrica - la hullera, la siderúrgica y la naviera- y ninguna específicamente catalana; Bertrán y Musitu, DSC-CD, 10 de julio de 1916, núm. 48, p. 1261. Ferrer i Vidal, hombre clave en la patronal catalana, insistió en no atribuirse «representación de ninguna clase»; Ferrer i Vidal, $D S C-C D, 6$ de julio de 1916, núm. 45, p. 1163.

${ }^{20}$ Los argumentos de Cambó, en DSC-CD, 26 de junio de 1916, núm. 37, pp. 845 y ss. 
Le faltó valor y altura, contraatacando con chismorrerías y groserías en lugar de alzar gallardamente la bandera del interés general... El debate perdía altura cuando hablaba él desde el banco azul.» Aunque no pueda considerarse como un único factor explicativo, la mala sintonía entre ambos politicos hubo de afectar a las relaciones entre los liberales y la Lliga ${ }^{21}$.

Otra interpretación ha resaltado los condicionantes económicos del conflicto. Frente a las valoraciones individualistas, Alba, Cambó y los políticos que les secundaban perderían buena parte de su autonomía para convertirse en apéndices parlamentarios de grupos de presión económicos. Desde esta perspectiva, Cambó sería el portavoz de la burguesía industrial, comercial y financiera periférica, emergente durante la Primera Guerra Mundial, y Alba el de los agrarios castellanos. No cabe duda de que Cambó tenía una importante clientela política entre financieros e industriales y Alba entre los propietarios agrarios de Castilla. Ambos, en más de una ocasión, defendieron sus intereses en las Cortes. La argumentación, además, vendría avalada por la exención de la agricultura en la contribución sobre los beneficios extraordinarios. Sin embargo, dos argumentos impiden achacar, exclusivamente, el comportamiento de regionalistas y liberales, en 1916, a sus vínculos con los grupos de presión industriales, financieros o agrarios ${ }^{22}$.

En primer lugar, el análisis del conflicto entre la Lliga y el Partido Liberal en 1916 se ha visto mediatizado por la excesiva atención dedicada al Proyecto de ley de beneficios extraordinarios en detrimento del conjunto de los planes del ministro de Hacienda. Alba incluyó en su programa importantes medidas de promoción a la actividad comercial o industrial, como la creación de un Banco Español de Comercio Exterior o el Proyecto de auxilio a las industrias, una de las pocas iniciativas que se transformó en Ley debido, precisamente, al apoyo regionalista. Estos proyectos fueron recibidos con interés por organizaciones patronales, comerciales e industriales de todo el país, en especial por las Cámaras de Comercio e Industria de Barcelona y Fomento del Trabajo Nacional. Por el contrario,

${ }^{21}$ El conflicto personal entre Alba y Cambó, en Pabón (1952), pp. 444 y ss. Para García Delgado, Muñoz y Roldán «subrayar los aspectos personales de la discusión y de los diversos acontecimientos es confundir y enmascarar la verdadera entidad y naturaleza de la trama»; García Delgado, Muñoz y Roldán (1973), vol. I, p. 301. Marín Arce también califica como «simplista» el planteamiento de Pabón; Marín Arce (1990), p. 47. La cita de Cambó puede verse en Cambó (1987), p. 240.

${ }^{22}$ El enfrentamiento Alba-Cambó, como conflicto entre intereses agrarios e industriales, en Riquer (1979), pp. 91 y ss. La Lliga, como representante de la burguesía emergente en los años de la Gran Guerra, en García Delgado, Roldán y Muñoz (1973), pp. 255-322. 
el Proyecto de reforma de la Contribución Territorial o el de creación de Impuesto sobre el aumento de valor de los bienes inmuebles le enajenaron el respaldo agrario. Una de las condenas más feroces a la obra de Alba procede de Luis Marichalar, vizconde de Eza, propietario castellano y presidente de la Asociación de Agricultores Españoles. La imagen que los regionalistas ofrecieron de Santiago Alba en 1916, como un enemigo del desarrollo industrial apoyado exclusivamente por los propietarios agrarios castellanos, no se sostiene ${ }^{23}$.

En segundo lugar, las relaciones de la Lliga con las organizaciones patronales catalanas eran demasiado tensas como para considerar al partido de Cambó el portavoz natural de los empresarios. Los regionalistas reclamaban el monopolio de la defensa de los intereses económicos de Cataluña y la intermediación entre las organizaciones patronales catalanas y el Estado. Sin embargo, esta labor de mediación era incompatible con la estrategia de acoso y derribo adoptada contra los gobiernos de Dato y de Romanones entre 1915 y 1916, que entrañaba la ruptura de todo diálogo. Durante el verano de 1916 los empresarios catalanes se distanciaron de la política emprendida por la Lliga y decidieron establecer vías de comunicación directa con el Gobierno. A principios de septiembre la Cámara de Industria de Barcelona desplazó de su presidencia al regionalista Ferrer i Vidal, tras comunicarle «sus pensamientos favorables a los proyectos del señor Alba». El día 4, el conde de Caralt, empresario liberal y presidente de Fomento del Trabajo Nacional, manifestó el rechazo de su organización a la «la política obstruccionista de los regionalistas en las Cortes». Un dirigente de Fomento precisó que «aunque los regionalistas y las fuerzas económicas de Cataluña» hubieran «podido parecer confundidos», los primeros sólo «representaban a sus poderdantes, pero no a las fuerzas económicas, no al Fomento del Trabajo». Cambó se vio obligado a reconocer que Fomento no era «la Lliga» ni tenía «nada que ver con ella», aunque, precisaba, muchos de los regionalistas pertenecían «a Fomento del Trabajo». Desde esta posición, advirtió a Caralt que podría

${ }^{23}$ Fontana resta importancia a los proyectos agrarios de Alba; Fontana (1980), pp. 76-77. No obstante, la violenta reacción de las organizaciones agrarias demuestra que causaron un fuerte impacto en dichos medios. Véase Marichalar (1917). La Asociación General de Ganaderos consideraba, valorando globalmente el programa de Alba, que «los que han de contribuir en definitiva a soportar la carga que con dichos proyectos se impone al país son los agricultores y ganaderos», La Industria Pecuaria, 10 de noviembre de 1916. El apoyo de las Cámaras de Comercio e Industria de Barcelona y Fomento del Trabajo Nacional a los proyectos de auxilio a las industrias y Banco de Comercio Exterior, en $A C D$, legs. 433/10 y 434/2, y La Tribuna, 27 de septiembre de 1916. 
orquestar una campaña para forzar su expulsión de la jefatura de Fomento, algo que no pasó de ser una simple amenaza. La ruptura de la Lliga con la patronal catalana se dejó sentir en el ánimo regionalista e influyó en la necesidad de reforzar los contactos con las organizaciones patronales de otras regiones españolas, con el fin de recaudar fondos «para hacer frente a los gastos que ha de exigir la ruda campaña». Entre agosto y septiembre diputados regionalistas recorrieron varias localidades del norte de España, como Bilbao, donde los empresarios navieros no escatimaban esfuerzos económicos para combatir el Proyecto ${ }^{24}$.

La tercera propuesta historiográfica considera la obstrucción regionalista al Proyecto de ley de beneficios extraordinarios como parte de una estrategia política definida con anterioridad a la elaboración del Proyecto y continuada con posterioridad a éste, dirigida a erosionar el turno de partidos, con el fin de aumentar las cuotas de autogobierno de Cataluña. La coincidencia entre la obstrucción regionalista y la movilización patronal contra el Proyecto sería, por tanto, coyuntural y cabría inscribirla en lo que Fernando del Rey ha calificado como «instrumentación recíproca, parcial y limitada». Los empresarios se beneficiaron del acceso de la Lliga al centro de toma de decisiones políticas y ésta legitimó su estrategia antiturnista con la defensa de los intereses económicos afectados por el Proyecto. Los regionalistas y las organizaciones patronales coincidieron puntualmente, pero sus objetivos eran distintos. Incluso llegaron a ser contradictorios, como demuestra las escalada de tensión entre Fomento del Trabajo Nacional y la Lliga, a partir del verano de $1916^{25}$.

El punto de partida de la actitud de los regionalistas se sitúa en la creación de la Mancomunidad Catalana en abril de 1914. A partir de este momento el principal objetivo de la Lliga fue dotar de competencias políticas, económicas y culturales a la nueva institución. Entre 1914 y 1915, a instancias de la Junta Económica de la Mancomunidad, y respaldada por las organizaciones patronales catalanas, la Lliga negoció con el gobierno

${ }^{24}$ El mito del monopolio regionalista sobre la representación de intereses económicos en Cataluña ha sido desmontado por Fernando del Rey; Rey Reguillo (1992), pp. 748 y ss. La polémica entre Fomento y la Lliga puede seguirse a través de La Tribuna, $A B C$ y el Heraldo de Madrid, 4-28 de septiembre de 1916. La cita sobre la necesidad de buscar financiación para la campaña contra el Proyecto fuera de Cataluña, en La Tribuna, 22 de septiembre de 1916.

${ }^{25} \mathrm{El}$ análisis de la oposición regionalista a Santiago Alba como parte de una estrategia política previa a la redacción del Proyecto de ley de beneficios extraordinarios ha sido abordado por Mercedes Cabrera, en Cabrera, Comín, García Delgado (1989), pp. 90 y ss. La instrumentación recíproca, en Rey Reguillo (1992), pp. 685 y ss. 
conservador de Eduardo Dato la creación de una zona franca, exenta de aranceles de importación, en el puerto de Barcelona. Suspendidos los contactos tras el verano de 1915, con el fin de doblegar a Dato, los regionalistas iniciaron una campaña obstruccionista contra el Gobierno en el Congreso. El fracaso de las negociaciones minó la confianza de Cambó en que los gobiernos del turno aceptaran un aumento de las competencias de la Mancomunidad ${ }^{26}$.

Tras las elecciones liberales de abril de 1916 la desconfianza derivó en un enfrentamiento radical. Santiago Alba, todavía ministro de la Gobernación, preocupado por el precedente de la obstrucción regionalista al gobierno Dato, orquestó en Barcelona una gran coalición electoral que englobaba a liberales, conservadores, carlistas y republicanos, con el fin de combatir a la Lliga y reducir al mínimo su número de escaños. La maniobra fracasó. Los regionalistas obtuvieron 13 diputados, los mismos que en 1914, y las elecciones fueron consideradas como un triunfo personal de Cambó. La actitud de Alba indujo al líder regionalista a proseguir con la estrategia adoptada contra el gobierno conservador precedente. Mediante la obstrucción, la Lliga podía presionar a los gobiernos del turno y forzarles a incrementar las competencias de la Mancomunidad. Si no cedían, la acción de desgaste bloquearía la alternancia y permitiría la participación regionalista en los gobiernos nacionales. Desde allí, la Lliga podría otorgar a Cataluña lo que los partidos turnantes la negaban. Cambó resumía así esta estrategia: si liberales y conservadores no abrían el acceso al poder había «que aprovechar cualquier ocasión para debilitar a los dos partidos del turno y quitarles el poder de las manos». La obstrucción contra el gobierno Romanones tenía una segunda finalidad. Por su estrategia electoral, Alba se había convertido en el enemigo a batir. Los regionalistas querían un castigo ejemplar. De nuevo las Memorias de Cambó son elocuentes. «Nuestro propósito era llevar a Santiago Alba a un fracaso total, a fin de que el escarmiento fuera lo bastante notorio para que nadie más tuviera la tentación de hacer contra nosotros maniobras de cerco. Queríamos que no se aprobara ningún proyecto de todos los que él había presentado, ni tan sólo el Presupuesto» ${ }^{27}$.

${ }^{26}$ La obstrucción regionalista contra el Gobiemo Dato, en Olivari (1983), pp. 237 y ss.

${ }^{27}$ El temor de Alba al precedente regionalista contra el gobierno Dato, en Olivari (1983), pp. 237 y ss. Las citas de Cambó en Cambó (1987), pp. 235 y 245. Sobre la obstrucción como arma regionalista contra el turno de partidos véase Martorell Linares (1997). Poco antes de los debates del Proyecto de ley de beneficios extraordinarios, durante 
El bloqueo del Proyecto de ley de beneficios extraordinarios fue el resultado del primer embate regionalista contra el programa económico de Alba. Como muestran los cuadros 1 y 2, seis diputados regionalistas figuran entre los dieciséis que más enmiendas redactaron contra el Proyecto. En total, una cuarta parte de las enmiendas recibieron su apoyo. Pero la estrategia obstruccionista de la Lliga contra la obra de Alba no concluyó en este punto. Iniciada la campaña parlamentaria de otoño el día 2 de octubre de 1916, Cambó advirtió en el Congreso su disposición a obstruir el debate de cualquier proyecto de reforma tributaria, mostrándose a cambio dispuesto a consentir que se discutieran los proyectos de reforma administrativa o de fomento de la actividad económica. Tras el precedente de la obstrucción contra el Proyecto de ley de beneficios extraordinarios, temiendo perder el resto de su programa, Alba postergó sus proyectos fiscales. Entre el 3 y el 25 de octubre el Congreso aprobó cinco proyectos de reordenación administrativa. Su trámite no fue fácil: el Gobierno se enfrentó a las tácticas dilatorias de regionalistas y ciervistas. Del 27 de octubre al 20 de noviembre los ataques se dirigieron contra el Presupuesto extraordinario, un programa decenal de inversiones en infraestructuras. Conservadores y reformistas defendían la prioridad del debate del Presupuesto ordinario para 1917 frente al Presupuesto extraordinario. Iniciaron una dura campaña de fiscalización parlamentaria en la que pronto fueron desbordados por las prácticas obstruccionistas de la Lliga: en un mes sólo se aprobaron las inversiones correspondientes al Ministerio de la Presidencia ${ }^{28}$.

El 20 de noviembre Alba sacrificó el Presupuesto extraordinario para iniciar la discusión del Presupuesto ordinario para 1917. Éste debía ser aprobado antes del 31 de diciembre, ya que el Presupuesto vigente había sido prorrogado en 1915. Sin embargo, no hubo tregua. Los regionalistas reemprendieron la obstrucción. En esta ocasión su estrategia consistió en plantear diariamente cuestiones de procedimiento, ralentizando los debates presupuestarios. A mediados de diciembre Romanones intentó negociar con las minorías la celebración de una sesión permanente, que durara sin

la discusión del Mensaje de la Corona, la Lliga defendió un proyecto de autonomía política que incluía la elección de una Asamblea local, un poder ejecutivo responsable ante ella y el reconocimiento de la cooficialidad de la lengua autónoma. Un interesante compendio de las demandas regionalistas en estas fechas, en el monográfico de la revista España, "Qué es el catalanismo», núm. 74, 22 de junio de 1916.

${ }^{28}$ El ultimátum de Cambó y la respuesta de Alba en $D S C-C D$, núm. 56, 2 de octubre de 1916. 
interrupción hasta que el Presupuesto fuera aprobado por el Congreso. Tuvo que renunciar por la amenaza regionalista de presentar más de cuatrocientas enmiendas y ante la precisión de que cada una de ellas sería defendida «con un discurso de media hora». El 16 de diciembre el Congreso aceptó una propuesta de Maura: el Gobierno sometería a las Cortes el texto del Presupuesto de 1915. Sancionado por ambas Cámaras, se convertiría en el nuevo Presupuesto para 1917. La triquiñuela legal permitió solventar el conflicto constitucional, pero significó la derrota final de Alba que, según los objetivos declarados por Cambó, no había logrado hacer realidad ni siquiera su Proyecto de Presupuesto ${ }^{29}$.

\subsection{Los diputados vizcaínos y la representación de intereses económicos locales en el Parlamento}

Junto a la Lliga Regionalista un nutrido grupo de diputados pertenecientes a diversos partidos también intentó bloquear el trámite parlamentario del Proyecto. Justificaban su actitud en la defensa de los intereses económicos de los distritos por los que habían sido elegidos. Dentro de este grupo heterogéneo destacaba la representación de la provincia de Vizcaya en el Congreso. Cinco de sus seis miembros participaron de forma activa y coordinada en la obstrucción. La acción conjunta de los vizcaínos no constituía un hecho aislado en la práctica parlamentaria de la Restauración. Por el contrario, era habitual que los representantes de una provincia o territorio defendieran, unidos, las actividades económicas predominantes en sus distritos. Esta actitud fue descrita, en un momento del debate del Proyecto de ley de beneficios extraordinarios, por el diputado liberal de Zaragoza, Leopoldo Romeo, al señalar que existía «un medio ambiente electoral que condiciona(ba) forzosamente muchas actitudes en la Cámara». Por este motivo, proseguía, «los diputados que representa(ba)n a un país triguero» tenían «puntos de vista distintos de los que representa(ba)n a países industriales, y los que representa(ba)n países fruteros» tenían «puntos de vista distintos de los que representa(ba)n distritos mineros» ${ }^{30}$.

${ }^{29} \mathrm{El}$ artículo 85 de la Constitución obligaba a las Cortes a aprobar un Presupuesto anual que sólo podía ser prorrogado una vez por Decreto. Sobre la estrategia obstruccionista de la Lliga tras el 20 de noviembre, El Imparcial, 30 de noviembre de 1916; La Época, 7 de diciembre de 1916. Amenazas regionalistas contra la sesión permanente, en La Epoca, 6 de diciembre de 1916.

${ }^{30} \mathrm{La}$ acción coordinada de los parlamentarios vizcaínos ya ha sido resaltada por Valdaliso (1990). Leopoldo Romeo, DSC-CD, núm. 47, 8 de julio de 1916, p. 1229. 
Al debatirse en el Parlamento el régimen fiscal sobre una actividad económica predominante en uno o varios distritos era habitual que sus diputados intervinieran en defensa de los intereses de sus electores, entendiendo por éstos no tanto a quienes ejercían el derecho al voto como a quienes por su relevancia política, social y económica podían influir en los resultados electorales. Además, generalmente, lo hacían unidos, con independencia de que militaran en distintos partidos o de que éstos fueran dinásticos o no. De este modo, la división del Parlamento en función de intereses económicos regionales se superponía a la organización por partidos políticos. En 1907, 1910 ó 1914 la discusión del régimen fiscal sobre el azúcar dividió al Congreso en grupos de diputados unidos por el tipo de materia prima azucarera predominante en cada territorio. Los parlamentarios de las costas de Granada y Málaga representaron los intereses de los productores de caña de azúcar de sus distritos, contrarios a los de los cultivadores de remolacha de la cuenca del Ebro, defendidos, a su vez, por los diputados aragoneses. Entre 1904 y 1908 los intentos de imponer una tributación fuerte al alcohol fracasaron por la presión de los diputados de los distritos de producción vitivinícola. Cada vez que se abordaba el espinoso problema de la zona franca del puerto de Barcelona los diputados castellanos, en nombre de los intereses cerealeros de sus distritos, chocaron con los diputados catalanes. Lo mismo ocurría con otras actividades agroalimentarias o con la minería. La unión de los diputados vizcaínos contra el Proyecto de ley de beneficios extraordinarios, en defensa de los intereses económicos de su territorio, se enmarca en este contexto ${ }^{31}$.

Dos tipos de motivaciones podían impulsar a un conjunto de parlamentarios a agruparse en la defensa de intereses económicos locales. Una primera razón de peso era su imbricación en ellos. En la movilización de varios diputados y senadores contra decisiones político-fiscales que perjudicaran a sectores predominantes de la economía de un territorio era habitual que al menos uno de ellos combinara su carrera política con una fuerte implicación en la economía local. El espléndido análisis de las actividades políticas y económicas de la rama sevillana de la familia Ybarra, llevado a cabo por María Sierra, abre una interesante línea de investigación

${ }^{31}$ Algunos de estos ejemplos están más documentados en Martorell Linares (1996b). Consideraciones sobre la representación de intereses vitivinicultores en las Cortes y su incidencia sobre la legislación fiscal,, en Pan Montojo (1994), pp. 290 y ss., y Puig Raposo (1994), pp. 117 y ss. Véase también Rull (s.f.). Para la representación parlamentaria de intereses azucareros véase Martorell Linares (1996a). Los conflictos entre diputados castellanos y catalanes por la zona franca del puerto de Barcelona, en Colomines (1993). 
sobre los vínculos entre ambas esferas en el sistema político de la Restauración. Quizá la figura del empresario-político no fuera cuantitativamente importante, pero no procede descartar su relevancia en términos cualitativos. Un político que participara en la economía local podía ser el mejor árbitro de ésta ante el Estado. Evidentemente no todos los diputados eran empresarios, por lo que también cabría apuntar otro tipo de razones de índole política. Los parlamentarios que defendían los intereses económicos locales podían actuar impulsados por compromisos con sus electores o clientelas, por el miedo a que la desatención de éstos pudiera hacer que buscaran mejores abogados ante el poder central o porque la defensa de los intereses generales de un territorio podía ser una buena catapulta política ${ }^{32}$.

Por otra parte, cabe resaltar que la presión sobre los diputados aumentaba cuando los productores locales habían alcanzado una cierta capacidad de movilización. La existencia de grandes organizaciones patronales de ámbito local como Fomento del Trabajo Nacional, el Círculo Minero de Bilbao o la Asociación de Labradores de Zaragoza, por poner algunos ejemplos, facilitaba un acción coordinada de los empresarios. Pero no siempre era precisa la existencia de grandes entidades. En ocasiones bastaba con la proliferación de pequeñas agrupaciones, como sindicatos, cooperativas o círculos de labradores. Éste fue el caso, por ejemplo, de los viticultores manchegos, que entre 1904 y 1908 demostraron una fuerte capacidad de movilización —su presencia en Madrid cada vez que se debatía la fiscalidad sobre el alcohol era masiva - y una gran influencia sobre los diputados de sus distritos ${ }^{33}$.

Estas condiciones se dieron en Vizcaya durante la tramitación del Proyecto de ley de beneficios extraordinarios. En primer lugar había una importante actividad económica local afectada por el Proyecto. Debido a su extraordinario crecimiento durante el primer año de guerra, el sector naviero de Bilbao era uno de los principales damnificados por la iniciativa de Alba. En segundo lugar existía una fuerte organización patronal dispuesta a movilizar recursos - humanos y económicos- en su defensa. La Asociación de Navieros de Bilbao impulsó el Comité de Organismos Económicos de Vizcaya, en el que participó la mayoría de las organizaciones patronales vizcaínas, y financió con 288.696 pesetas sus actividades. Dicha

${ }^{32}$ Sobre la participación activa de los empresarios en la política véase Sierra (1992).

${ }^{33}$ Como ejemplo de la movilización de los vitivinicultores de La Mancha y Levante véase el caso de 1904, en $A C D$, leg. 340/47; en El Imparcial y en El Liberal, 1-4 de junio de 1904. 
cantidad se invirtió en «gastos de viajes correspondencia postal, telegráfica y telefónica; ediciones de folletos, con informes y colección de enmiendas». En tercer lugar, la participación activa de empresarios fue una característica de la política vizcaína durante las últimas décadas del siglo $\mathrm{xx}$ y las primeras del xx. En la representación parlamentaria de 1916 los casos más notorios eran los de Horacio Echevarrieta, Fernando Ibarra y José María Chávarri, empresarios asociados al sector naval, minero y metalúrgico. Echevarrieta, diputado republicano y presidente de la Cámara de Comercio de Bilbao, fue el delegado de ésta en el Comité de Organismos Económicos de Vizcaya, lo que le permitía actuar como enlace entre la patronal y los diputados vizcaínos ${ }^{34}$.

Durante el trámite del Proyecto en el Congreso los diputados de Vizcaya se unieron en defensa de los navieros. En otoño, postergados los debates parlamentarios del Proyecto, Alba entró en negociaciones directas con las organizaciones patronales. Éstas se extendieron entre octubre y enero de 1917 y se saldaron con un rotundo fracaso. Las principales críticas de los navieros eran tres: rechazo a la retroactividad y a la exención de la agricultura y acusaciones de vulneración del concierto económico con el País Vasco. La condena de la retroactividad era común a todo el espectro patronal. La razón del rechazo era, a su juicio, obvia: no se podía obligar a un empresario a pagar un tributo que no entraba en sus previsiones de costos. La retroactividad, afirmaba Echevarrieta, haría que nadie fuera «capaz de lanzarse a nuevas empresas desafiando atentados del fisco e inseguridades de los negocios». Además, en el caso de los navieros, parte de los beneficios de 1915 ya habían sido redistribuidos en forma de incrementos salariales. El informe del Instituto de Reformas Sociales sobre la marcha de la economía española en el segundo año de guerra apuntaba que «todo el personal de la Asociación de navieros (desde el capitán al último marinero)» percibía «aparte del sueldo o jornal, el 3 por 100 de

${ }^{34} \mathrm{El}$ crecimiento del sector naviero vizcaino al principio de la guerra, en Instituto de Reformas Sociales (1916), pp. 66 y ss. Las inversiones de la Asociación de Navieros de Bilbao en el Comité, en $A A$, leg. 3/40. Sobre los informes remitidos por las organizaciones del Comité a la Comisión parlamentaria véase En defensa de los intereses económicos (1916). La actitud de los navieros vizcaínos ante el Proyecto, en García Delgado, Roldán y Muñoz (1973) y Valdaliso (1990). La organización de los empresarios vascos, en Olábarri (1978), Arana (1988), Rey Reguillo (1992), pp. 762 y ss. Los vinculos entre los empresarios vizcaínos y la política, en Fusi (1975), pp. 108 y ss. 
las utilidades líquidas» que se repartía «en proporción al haber de cada uno» ${ }^{35}$.

Sin embargo, a pesar de los estrechos vínculos de los diputados vizcaínos con las actividades económicas predominantes en sus distritos, su recurso a la obstrucción sólo puede ser entendido en virtud de otras dos razones, de índole política. La primera reside en la filiación de la representación parlamentaria vizcaína, entre la que predominaban los diputados independientes o adscritos a pequeñas formaciones. Desde la oposición, conservadores y liberales procuraban evitar la obstrucción - no siempre lo hacían-, un arma que podía volverse en su contra al producirse la alternancia. Por el contrario, los diputados de partidos no-turnantes tenían menos ataduras. De los seis diputados de Vizcaya, Echevarrieta era republicano, Ibarra maurista, Ampuero jaimista y Acillona independiente. Chávarri y Andrés Allendesalazar, conservadores, fueron más moderados. Como puede verse en el cuadro 1, Chávarri no participó activamente en la obstrucción mediante la presentación de enmiendas y Allendesalazar suscribió un menor número que sus compañeros. Este último, además, votó en alguna ocasión junto a su partido en apoyo al Gobierno. La segunda razón estaba relacionada con el tenso clima político. Fueron los regionalistas quienes impulsaron la obstrucción contra el Proyecto de ley de beneficios extraordinarios. Los vizcaínos, junto con otros diputados que rechazaban el Proyecto, azuzados por sus electores en sus distritos, asumieron su estrategia agresiva. El cuadro 2 muestra la iniciativa regionalista en la mayoría de las enmiendas. La Lliga coordinó la acción conjunta de catalanes y vizcaínos, que, por ejemplo, el 2 de octubre se reunieron en casa de Cambó para acordar su actitud si Alba decidía proseguir con el Proyecto. Los empresarios vizcaínos reconocieron el protagonismo regionalista en la campaña de obstrucción y dispensaron una impresionante acogida a Cambó en Bilbao en febrero de 1917. La «organización de los diversos actos del señor Cambó» en estas fechas fue financiada por la Asociación de Navieros de Bilbao ${ }^{36}$.

39 Sobre la coordinación de los diputados vizcaínos véase el discurso de Ibarra, DSC-CD, núm. 47, 8 de julio de 1916, p. 1221. Ibarra, Echevarrieta y Ampuero consideraban que el Proyecto iba dirigido expresamente contra el sector naval, $D S C-C D$, núm. 37, 26 de junio de 1916, pp. 839 y ss., y $D S C-C D$, núm. 45, 6 de julio de 1915, p. 1149. Para la cita de Echevarrieta véase En defensa de los intereses económicos (1916), p. 25. Instituto de Reformas Sociales (1916), p. 66. El aumento de salarios en el sector naviero, en Valdaliso (1990).

${ }^{36}$ Allendesalazar votó con los conservadores cuando el Gobierno solicitó la prórroga de las sesiones, $D S C-C D$, núm. 48, 10 de julio de 1916, p. 1273. La reunión en casa de 
Los representantes de la provincia de Vizcaya no fueron los únicos que participaron en la obstrucción al Proyecto, alegando la defensa de los intereses económicos de sus distritos. Los cántabros Solana y Ruano, tradicionalista y conservador, aunque suscribieron menos enmiendas que los vizcaínos -diecinueve y quince, respectivamente- contribuyeron a entorpecer el ritmo de los debates con discursos farragosos, en nombre de «las industrias de la ciudad de Santander». Solana provocó un ruidoso incidente cuando, para argumentar una enmienda, comenzó a disertar acerca del concepto de justicia en la obra de Aristóteles y su influencia en la filosofía occidental. Los abucheos de la mayoría liberal y los llamamientos al orden del presidente de la Cámara le obligaron a abstenerse de proseguir sus reflexiones filosóficas. Luis Alvarado, diputado de la provincia de Málaga, suscribió veintidós enmiendas e intervino en los debates «en nombre de las entidades fabriles que radican en el distrito que represento». Tenía argumentos sólidos para luchar contra el Proyecto, pues dirigía una de las fábricas de azúcar de caña propiedad de la familia Larios, en la costa malagueña, y el sector azucarero figuraba entre los más beneficiados por la guerra ${ }^{37}$.

\section{OTRAS ACTITUDES ANTE EL PROYECTO. CONSERVADORES, REPUBLICANOS Y LIBERALES}

El 28 de junio de 1916 los industriales y financieros asistentes a la Asamblea del Hotel Palace de Madrid celebraron una reunión en el Congreso de los Diputados con representantes de todas las minorías parlamentarias. A la cita acudieron conservadores, mauristas, ciervistas, regionalistas y los grupos de la extrema derecha. Los conservadores, aseguró Dato a los comisionados, «se habían mostrado antes que nadie contrarios al Proyecto, tanto en la forma como en el fondo». Maura «expuso su opinión de que el Proyecto» era «una gran injusticia» y recomendó a los reunidos que redactasen enmiendas que, «después de estudiadas, ser(í)an presentadas por los diputados». Senante y Llosas, integrista y jaimista, ratificaron las palabras de Maura. Cierva se mostró convencido de que

Cambó, en La Época, 2 de octubre de 1916. La financiación de los actos de recibimiento a Cambó en Bilbao, en $A A$, leg. 3/40.

37 Ruano, Solana y Alvarado, respectivamente, en $D S C-C D$, núm. 42, 3 de julio de 1916, p. 1060; núm. 46, 7 de julio de 1916 , p. 1199 y ss., y núm. 48,10 de julio de 1916, p. 1286. 
con el Proyecto «el interés público» resultaba «lesionado». Cambó reiteró las críticas vertidas en el Congreso pocos días antes. La coincidencia en el tono de los discursos pudo inducir a García Delgado, Roldán y Muñoz a considerar que existió también una unidad de acción en las estrategias adoptadas por los partidos de la derecha parlamentaria. El seguimiento de los debates permite comprobar que sólo los regionalistas, con la ocasional colaboración de las minorías de la extrema derecha, optaron por la obstrucción ${ }^{38}$.

Conservadores, mauristas y ciervistas aunque combatieron el Proyecto no participaron en la obstrucción al mismo. Gabino Bugallal, portavoz conservador en los debates, era tajante al respecto: «no hablemos de obstrucción, porque la oposición conservadora no la entiende lícita en un caso como el actual». En realidad, Bugallal no tenía argumentos para secundar la campaña obstruccionista, ya que, como él mismo reconocía ante la Cámara, el año anterior había pensado llevar al Congreso un proyecto similar. El Partido Conservador combinó el rechazo a la iniciativa de Alba con una permanente oferta de negociación, con una sola condición: la renuncia a la retroactividad. Al rechazar dicha imposición, Alba cerró la posibilidad de consensuar el Proyecto con los conservadores. Los mauristas -excepción hecha del vizcaíno Fernando Ibarra-y los ciervistas adoptaron una posición similar. Como indicaba el diario $A B C$, la clave residía en la retroactividad; «al llegar a este punto... se produce el apoyo unánime de todas las fuerzas conservadoras». Integristas, jaimistas y tradicionalistas fueron los grupos de la derecha más próximos a la estrategia de regionalistas y vizcaínos. El cuadro 1 muestra cómo los jaimistas Ampuero, Bilbao y Llosas y el tradicionalista Domínguez Arévalo figuran entre los diputados que más enmiendas suscribieron. No obstante, los cuadros 1 y 2 reflejan también que pocas partieron de su iniciativa y que se limitaron a firmar textos ya redactados. Excluyendo a Ampuero, diputado por Vizcaya, de la extrema derecha parlamentaria sólo partieron 10 enmiendas, sobre un total de 140 . Un simple 5 por 100 , cinco veces menos que regionalistas o vizcaínos 39 .

En el otro extremo ideológico, aun cuando era de esperar una cierta sintonía dado el carácter progresista del Proyecto, ninguno de los tres

38 Las declaraciones de los diputados, en La Época, 28 de junio de 1916.

39 Las negociaciones entre Alba y los conservadores, en $A B C$, 9 de julio de 1916; $L a$ Época, 11 de julio de 1916; $D S C-C D$, núm. 49, 11 de julio de 1916, p. 1307. Cierva rechazó expresamente la obstrucción, $D S C-C D$, núm. 46,7 de julio de 1916, p. 1192. La última cita, en $A B C, 5$ de julio de 1916. 
grupos republicanos respaldó con firmeza a Santiago Alba. Quienes más cerca estuvieron del ministro de Hacienda fueron los republicanos reformistas, aunque renegaron de algunas decisiones del Gobierno, como el Decreto del 21 de junio, que ponía en vigor parte del Proyecto. Republicanos reformistas y conjuncionistas votaron con los liberales contra las enmiendas redactadas por regionalistas y vizcaínos. Los primeros, más moderados y gubernamentales, apoyaron la fórmula de transacción ofertada por Alba a las minorías el 11 de julio. Los conjuncionistas, por el contrario, negaron su respaldo al Gobierno. Aunque aceptaban, según explicaba Aniceto Llorente, «el criterio, el principio, la idea, la orientación que inspira el Proyecto, es decir, el impuesto sobre beneficios extraordinarios obtenidos con ocasión de la guerra», rechazaban su «desarrollo técnico». No obstante, los republicanos radicales de Lerroux fueron quienes mostraron la actitud más voluble. A diferencia de las otras familias republicanas, Lerroux respaldó al Gobierno cuando se discutió la legalidad del Decreto del 21 de junio. Sin embargo, el 11 de julio, cuando Alba presentó su propuesta de transacción, dio un giro de 180 grados. Con las modificaciones propuestas, apuntaba el político radical, el Proyecto ya no podía satisfacer a nadie, «porque bien pudiera decirse, como el poeta, que lo habéis dejado imposible para vos y para mí» ${ }^{40}$.

La tramitación del Proyecto no acentuó las diferencias entre los distintos grupos que integraban la mayoría, pero algunos detalles permiten deducir que el respaldo liberal al Proyecto no fue todo lo entusiasta que el Gobierno hubiera querido. De entrada, Romanones se enfrentó a un grave problema de disciplina, ya que la puntualidad y la asistencia liberal a los debates dejó mucho que desear. Sólo la abstención de las oposiciones permitió al Gobierno ganar una moción de confianza el 26 de junio, pues en ese momento únicamente había en el Congreso 152 de los 224 diputados que integraban la mayoría. El 3 de julio acudieron a la Cámara suficientes liberales como para cubrir el quórum necesario para abrir la sesión, pero poco después muchos abandonaron el hemiciclo para asistir a la corrida de toros de la Beneficencia, dejando en mayoría a las oposiciones. El 4 de julio La Tribuna daba constancia de «la desanimación que ofrec(ía) la Cámara». Es difícil medir hasta dónde el absentismo representaba el habitual desinterés de los diputados por los debates económicos o era una

${ }^{40} \mathrm{El}$ rechazo reformista al Decreto del 21 de junio, en El Imparcial, 27 de junio de 1916. Los argumentos conjuncionistas para rechazar la propuesta de Alba del 11 de julio, en Llorente, $D S C-C D$, núm. 50, 12 de julio de 1916, p. 1353. Alejandro Lerroux, DSC-CD, núm. 50, 12 de julio de 1916, p. 1346. 
muestra de disconformidad con la iniciativa gubernamental. Alfonso Sala, diputado liberal catalán e importante dirigente empresarial, no participó en la moción de confianza del Gobierno del 26 de junio ni asistió a ninguna otra sesión parlamentaria. Sin embargo, el 28 de junio Sala estaba en Madrid y acudió a la Asamblea convocada en el Hotel Palace. En este caso cabe sospechar que el absentismo fue una opción política que expresaba su discrepancia frente al Proyecto. Otros parlamentarios liberales, por razones ideológicas, por vinculación con intereses empresariales o en respuesta a agravios gubernamentales podrían hallarse en situación semejante $^{41}$.

\section{CONCLUSIONES}

En relación a las propuestas apuntadas en la introducción a este artículo cabe hacer tres consideraciones. En primer lugar, no fue la movilización patronal la que indujo a la Lliga Regionalista a liderar la campaña de obstrucción al Proyecto de ley de beneficios extraordinarios. La oposición de la Lliga a la obra de Alba fue parte de una estrategia política dirigida a debilitar el turno de partidos, percibido por los regionalistas como un obstáculo para el desarrollo de mayores cuotas de autogobierno para Cataluña. Esta estrategia se había iniciado el año anterior, contra el gobierno Dato, y se prolongó a lo largo de todo el ejercicio parlamentario de 1916. El resultado final fue el fracaso global del programa económico de Alba. El seguimiento de los debates parlamentarios permite constatar la continuidad entre la actitud de la Lliga frente al Proyecto de beneficios extraordinarios y ante el resto de los planes económicos de Alba. Las relaciones entre los regionalistas y las organizaciones patronales se inscriben en lo que Fernando del Rey ha calificado de «instrumentación recíproca, parcial y limitada». Los grupos de presión se beneficiaron del acceso regionalista al proceso de toma de decisiones y la Lliga legitimó su estrategia de acoso y derribo al turno de partidos mediante un discurso que presentaba la pervivencia del gobierno liberal como un obstáculo al desarrollo económico impulsado por la guerra.

En segundo lugar, otros diputados, entre los que destacaron los vizcaínos, también participaron en la obstrucción, junto a la Lliga

${ }^{41}$ La cita es de La Tribuna, 4 de julio de 1916. En el caso de Sala podían influir otras razones, ya que poco antes había dimitido de la Dirección General de Comercio; véase Joaniquet (1955). 
Regionalista. Su actitud se enmarca en un modelo común en la práctica política de la Restauración: la defensa de intereses económicos locales en el Parlamento. Para estos diputados la obstrucción respondía a un contrato de naturaleza política con los electores y clientelas de sus distritos. Algunos de ellos eran empresarios perjudicados por la iniciativa de Alba, erigidos en defensores de sus semejantes. El hecho de que la mayoría de los parlamentarios que participaron en la obstrucción pertenecieran a partidos no-dinásticos influyó en su virulenta actitud contra el Proyecto. Como muestra el cuadro 1, entre los dieciséis diputados que suscribieron un mayor número de enmiendas sólo tres pertenecían al Partido Conservador y uno era maurista. El resto eran regionalistas, tradicionalistas, jaimistas e independientes.

En tercer lugar, sólo regionalistas, vizcaínos y algunos diputados aislados, cuya actitud se desarrolló al margen de la estrategia de sus partidos, participaron en la obstrucción. Los conservadores y sus disidencias combatieron el Proyecto, pero no renunciaron al diálogo con el Gobierno, al que impusieron una única condición: el rechazo a la retroactividad. Alba, por el contrario, no siempre se mostró dispuesto a negociar con las oposiciones, que fueron excluidas de la Comisión parlamentaria encargada de emitir el dictamen. Sólo cuando se vio acosado, el 11 de julio de 1916, ofreció una propuesta de transacción a la Cámara. Aunque recogía algunas de las demandas expuestas en las enmiendas no renunciaba a la retroactividad del impuesto, condición exigida por los conservadores y las organizaciones patronales. En esta batalla Alba no obtuvo el apoyo resuelto que cabría esperar de los republicanos, dado el carácter progresista de la iniciativa.

Entre la clase política de la Restauración prevalecía el convencimiento de que el fracaso del Proyecto de ley de beneficios extraordinarios y del conjunto de la obra de Alba había sido posible porque existía un desfase entre las normas que regían el funcionamiento del Parlamento desde los primeros años de la Restauración y una realidad politica cambiante. Un editorial de El Imparcial, en diciembre de 1916, daba cuenta de «la necesidad de reformar el Reglamento de las Cortes en términos que impidan la obstrucción arbitraria de cualquier fuerza del Parlamento». El problema residía en que «en la vida política española no exist(ía)n ya sólo dos partidos... interesados ambos en el buen orden y eficacia de los debates». Mientras que los dos grandes partidos se mantuvieron unidos y las minorías se resignaron a ocupar posiciones marginales hubo un cierto consenso sobre las normas que debían regir las relaciones entre los actores 
políticos implicados en la vida parlamentaria. Cuando las minorías cuestionaron el monopolio ejercido por liberales y conservadores en el acceso al Gobierno, el consenso se quebró. Roto el consenso, cualquier Gobierno era un Gobierno débil. Con los reglamentos parlamentarios vigentes en 1916 el Ejecutivo no podía imponer su criterio al Legislativo. Las minorías, como se ha podido comprobar a lo largo del artículo, tenían numerosos recursos para dilatar u obstruir la tramitación de un Proyecto. En 1918 una de las primeras tareas del gobierno nacional de Antonio Maura fue llevar al Congreso y al Senado nuevos reglamentos que reforzaban el poder del Ejecutivo frente al Legislativo y recortaban las posibilidades obstruccionistas de las minorías. La reforma, que contó con el consenso mayoritario de la clase política, permitió que prosperaran en las Cortes las reformas tributarias de 1920 y $1922^{42}$.

La movilización patronal no bastó para hacer fracasar el Proyecto de Alba. Los grupos de presión económicos necesitaban aliados políticos en las Cortes. En 1916 contaron con la conjunción de un Gobierno débil, un Parlamento en crisis y un eficaz valedor - la Lliga Regionalistaembarcado en una estrategia de erosión del turno de partidos. Pero no siempre tuvieron tanta suerte. La agresividad de la movilización empresarial de 1916 fue superada en dos ocasiones durante el primer cuarto del siglo XX. La primera, en 1899, contra la reforma tributaria de Villaverde. El liberal Francos Rodríguez recordaba que en aquella ocasión «se reunieron las Cámaras de carácter económico, hubo asambleas de sociedades y los grandes intereses se acumularon en son de protesta». Pese a ello, el Proyecto de ley de creación de la contribución de utilidades, objetivo de las quejas, «se examinó y votó en dos tardes consecutivas, se pronunciaron tres o cuatro discursos, se discutieron algunas enmiendas y no pasó más». La segunda ocasión fue entre 1920 y 1922 . La protesta patronal contra las reformas tributarias de Bugallal y Cambó-Bergamín marcó un punto de inflexión en la ruptura de las relaciones entre empresarios y políticos en la Restauración. No obstante, con ciertas modificaciones, las Cortes las aprobaron porque todos los grupos parlamentarios reconocían la necesidad de las mismas. A diferencia de lo ocurrido en 1916, en 1899

${ }^{42}$ Comín (1996), tomo II, p. 121, El Imparcial, 21 de diciembre de 1916. Véanse también las propuestas de reforma del liberal Royo Villanova, en El Imparcial, 4 de enero de 1917. Sobre la reforma del Reglamento de 1918, Cabrera (1996). Sobre la crisis del consenso parlamentario, Martorell (1997). 
y 1920-1922 las organizaciones patronales no encontraron aliados eficaces en las Cortes ${ }^{43}$.

\section{APÉNDICES}

\section{CUADRO 1}

La obstrucción, mediante enmiendas, al Proyecto de ley de beneficios extraordinarios 44

\begin{tabular}{|c|c|c|c|c|c|}
\hline \multirow{2}{*}{ Diputados } & \multicolumn{3}{|c|}{ Enmiendas } & \multirow{2}{*}{ Filiación } & \multirow{2}{*}{ Provincia } \\
\hline & $I N C^{1}$ & $S U S^{2}$ & $T O T^{3}$ & & \\
\hline Horacio Echevarrieta .... & 14 & 44 & 58 & Republicano Indep. & Vizcaya \\
\hline J. Pablo de Acillona....... & 7 & 51 & 58 & Independiente & Vizcaya \\
\hline J. Joaquín de Ampuero.. & 3 & 55 & 58 & Jaimista & Vizcaya \\
\hline Esteban de Billbao .......... & 2 & 48 & 50 & Jaimista & Guipúzcoa \\
\hline Fernando Ibarra ............. & 7 & 42 & 49 & Maurista & Vizcaya \\
\hline Juan Ventosa .................. & 6 & 43 & 49 & Regionalista & Gerona \\
\hline Luis Ferrer Vidal ............ & 7 & 32 & 39 & Regionalista & Barcelona \\
\hline T. Domínguez Arévalo.. & 3 & 33 & 36 & Tradicionalista & Navarra \\
\hline Pedro Llosas..................... & 2 & 29 & 31 & Jaimista & Gerona \\
\hline Alberto Rusiñol............... & & 31 & 31 & Regionalista & Barcelona \\
\hline J. Bertrán Musitu ........... & 12 & 14 & 26 & Regionalista & Barcelona \\
\hline Andrés Allendesalazar ... & 3 & 23 & 26 & Conservador & Vizcaya \\
\hline J. María Méndez Vigo... & 1 & 24 & 25 & Conservador & Navarra \\
\hline Buenaventura Plaja ........ & & 23 & 23 & Regionalista & Barcelona \\
\hline Luis Alvarado .................. & 4 & 18 & 22 & Conservador & Málaga \\
\hline Magín Morera ................ & 2 & 19 & 21 & Regionalista & Barcelona \\
\hline
\end{tabular}

LEYENDA: INC: Enmiendas de iniciativa personal; SUS: Enmiendas suscritas a iniciativa de otro diputado; TOT: INC + SUS.

FUENTE: DSC-CD, 3 de junio-13 de julio de 1916, y Base de datos sobre personal parlamentario entre 1914-1923, elaborada por Mercedes Cabrera, Luis Arranz y Fernando del Rey.

${ }^{43} \mathrm{La}$ cita de Francos Rodríguez, en DSC-CD, núm. 45, 6 de julio de 1916, p. 1152. La movilización patronal contra Villaverde, en Besses (1901) y Camps (1961). Contra las reformas tributarias de 1920-1922, Rey Reguillo (1992), pp. 283 y ss.

${ }_{44} \mathrm{La}$ presentación de enmiendas no siempre presupone una actitud hostil contra un Proyecto de ley. Para marcar las diferencias entre la obstrucción y la simple voluntad de modificar algunos aspectos del Proyecto el cuadro sólo incluye a los diputados de tomaron la iniciativa en la redacción de más de veinte enmiendas. Las enmiendas se presentaban a iniciativa de un diputado y necesitaban ser suscritas por otros seis. 


\section{CUADRO 2}

Enmiendas a iniciativa de cada grupo parlamentario ${ }^{45}$

\begin{tabular}{|c|c|c|}
\hline Grupo parlamentario & $\begin{array}{c}\text { Nümero } \\
\text { de enmiendas }\end{array}$ & $\begin{array}{c}\text { Porcentaje } \\
\text { del total }\end{array}$ \\
\hline 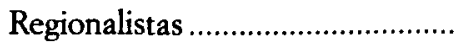 & 38 & 27 \\
\hline Diputados vizcaínos..................... & 34 & 24 \\
\hline Conservadores .............................. & 24 & 17 \\
\hline 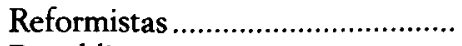 & 10 & 7 \\
\hline Republicanos .............................. & 9 & 6 \\
\hline 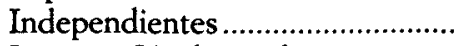 & 9 & 6 \\
\hline Jaimistas/Tradicionalistas............ & 7 & 5 \\
\hline 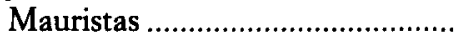 & 6 & 4 \\
\hline 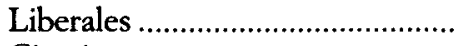 & 3 & 2 \\
\hline 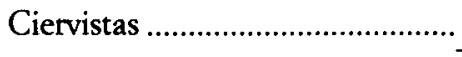 & 0 & 0 \\
\hline TOTAL $\ldots \ldots \ldots \ldots \ldots \ldots \ldots \ldots$ & 140 & 100 \\
\hline
\end{tabular}

FuENTE: DSC-CD, 3 de junio-13 de julio de 1916, y Base de datos sobre el personal parlamentario entre 1914-1923, elaborada por Mercedes Cabrera, Luis Arranz y Fernando del Rey.

\section{BIBLIOGRAFÍA}

ALBA, Santiago (1916): «Discurso de presentación del Plan económico y financiero en el Congreso de los Diputados», El Financiero, 6 de octubre de 1916, pp. 663-678.

- (1919): La Izquierda Liberal, Valladolid, imprenta castellana.

ArAna PÉrez, Ignacio (1988): La Liga Vizcaína de Productores y la politica económica de la Restauración, 1894-1914: relaciones entre el empresario y el poder politico, Bilbao, Caja de Ahorros Vizcaína.

Arranz, Luis, y Cabrera Calvo-Sotelo, Mercedes (1995): «El Parlamento de la Restauración», Hispania, vol. LV, 189, pp. 67-98.

- (1996): «Parlamento, sistema de partidos y crisis de Gobierno en la etapa final de la Restauración (1914-23)», Revista de Estudios Políticos, núm. 93, junio-septiembre, pp. 313-331.

BESSEs, Luis (1901): El año anterior. La política, el Parlamento, la prensa, la ciencia, el arte, la industria, el comercio y la clase obrera en 1900, Madrid.

Cabrera, Mercedes; Comin, Francisco, y Garcia Delgado, J. Luis (1989): Santiago Alba. Un programa de reforma económica en la España del primer tercio del siglo XX, García Delgado, J. Luis (ed.), Madrid, Instituto de Estudios Fiscales.

Cabrera, Mercedes (1995): «El Parlamento en la crisis de la Monarquía», Revista del Centro de Estudios Constitucionales, núm. 21, mayo-agosto, pp. 55-82.

45 Las enmiendas de los diputados vizcainos no se han contabilizado entre las de sus respectivos partidos políticos, para evitar duplicaciones. 
- (1996): «La reforma del Reglamento de la Cámara de Diputados en 1918», Revista de Estudios Políticos, núm. 93, junio-septiembre 1996.

CAmbó, Francisco (1987): Memorias. 1876-1936, Madrid, Alianza.

CAMps I ARBOIX, Joaquim (1961): El tancament de caixes, Barcelona, Dalmau.

Canals, Salvador (1916): «Contribución sobre las utilidades de la guerra», Nuestro Tiempo, agosto 1916, pp. 200-230.

Casais y Santaló, José (1917): La reorganización de la Hacienda Pública Española. Reformas político-económicas de D. Santiago Alba, Buenos Aires.

Ceballos Teresí, José G. (1916): «Resurgimiento económico y financiero de España. Los planes de Alba», El Financiero Hispano-Americano, 6 de octubre de 1916, pp. 658-663.

Colomines y Companys, Agustí (1993): El catalanisme y l'Estat. La lluita parlamentaria pel l'autonomía (1898-1917), Barcelona, Abadía de Montserrat.

Comín, Francisco (1988): Hacienda y economía en la España contemporánea, Madrid, Instituto de Estudios Fiscales.

- (1996): Historia de la Hacienda Pública, tomo I, Europa; tomo II, España (1808-1995), Barcelona, Crítica.

ESCUDERO, Antonio (1990): «El "lobby" minero vizcaíno», en Historia Social, núm. 7, pp. 39-69.

- (1994): «El fraude fiscal en la minería española (1876-1935)», en El fraude fiscal en la Historia de España, Comín, Francisco (ed.), Hacienda Pública Española, número monográfico, pp. 321-343.

En defensa de los intereses económicos (1916), Bilbao, Viuda e Hijos de Grijelmo.

Fontana, Josep (1980): La Hacienda en la Historia de España. 1700-1931, Madrid, Instituto de Estudios Fiscales.

Fuentes Quintana, Enrique (1990): Las reformas tributarias en España, Barcelona, Crítica.

Fusi, Juan Pablo (1975): Politica obrera en el País Vasco. 1880-1923, Madrid, Turner.

García DELGADO, José Luis; Roldán, Santiago, y MuÑoz, Juan (1973): La formación de la sociedad capitalista en España. 1914-1920, Madrid, Confederación Española de Cajas de Ahorro.

García LóPEZ, José Antonio (1984): «El programa económico financiero de Santiago Alba», Papeles de Economía Española, núm. 20, pp. 216-235.

García Venero, Maximiano (1963): Santiago Alba. Monárquico de razón, Madrid, Aguilar.

González PoSADA, Adolfo (s.f.): «Obstruccionismo», en Enciclopedia Jurídica Española, Barcelona (aprox. 1920).

InstTTUTO DE REFORMAS SOCIALES (1916): Informes de los inspectores del trabajo sobre la influencia de la guerra europea en las industrias españolas durante el año de 1915, Madrid.

JoAniquet, Aurelio (1955): Alfonso Sala y Argemi, conde de Egara, Madrid, Espasa. MARICHALAR, Luis (1917): Examen de un seudo plan económico, Madrid.

MARÍN ARCE, José María (1991): Santiago Alba y la crisis de la Restauración, Madrid, UNED.

Martorell Linares, Miguel Ángel (1996a): «Cañeros contra remolacheros y andaluces contra aragoneses: la representación de intereses en el Parlamento 
y la tributación sobre el azúcar en vísperas de la Primera Guerra Mundial», Agricultura y Sociedad, núm. 79, abril-junio 1996.

- (1996b): «Gobiernos, mayorías parlamentarias y representación de intereses en la Crisis de la Restauración», Documento de Trabajo del Seminario de Historia Contemporánea del Instituto Universitario Ortega y Gasset, núm. 2/96.

- (1997): «La crisis parlamentaria de 1913-1917. La quiebra del sistema de relaciones parlamentarias de la Restauración», Revista de Estudios Políticos, abril-junio 1997.

- (en prensa): «Las reformas tributarias y la política en España en el primer cuarto del siglo xx», La reforma de Mon-Santillán, 150 años después, Сomín, Francisco (ed.), Hacienda Pública Española, número monográfico.

Morlino, Leonardo (1992): «Partidos políticos y consolidación democrática en el Sur de Europa», en Las transformaciones de lo político, BENEDICTO Y REINARES (ed.), Madrid, Alianza, pp. 35-76.

OlÁBARRI GORTÁZAR, Ignacio (1978): Relaciones laborales en Vizcaya (1890-1936), Durango.

OLIVARI, Michele (1983): Regionalismo catalano, stato e padroni fra il 1898 e il 1917, Milán, Franco Angeli Editore.

Pabón, Jesús (1952): Cambó (1876-1918), Barcelona.

PAN-Montojo, Juan (1994): La bodega del mundo. La vid y el vino en España (1800-1936), Madrid, Alianza.

Pérez-Serrano Jáuregui, Nicolás (1983): «La obstrucción parlamentaria», Revista Española de Derecho Constitucional, núm. 8, mayo-agosto, p. 50.

Puig RaPoso, Nuria (1994): «Modernización y regulación. La industria alcoholera española, 1856-1953», en La cara oculta de la industrialización, NADAL y CATALÁN (eds.), Madrid, Alianza.

RAHOLA, Federico (1917): Comentarios a los proyectos tributarios del señor Alba, Barcelona, Tipografía La Académica.

Rey Regulllo, Fernando (1992): Propietarios y patronos. La politica de las organizaciones económicas en la España de la Restauración, Madrid, Ministerio de Trabajo.

Rey Reguillo, Fernando, y Moreno Luzón, Javier (1996): «Semblanza de la élite parlamentaria en la crisis de la Restauración», Revista de Estudios Politicos, núm. 93, junio-septiembre 1996, pp. 177-205.

RuQUER, Borja de (1979): Regionalistas y nacionalistas (1898-1931), Barcelona, Dopesa.

Ríu, Emilio (1916): «El plan financiero de Santiago Alba», Revista Nacional de Economia, núm. 3, agosto-septiembre 1916, pp. 3-24.

Rull, Gregorio (s.f.): El gravamen de los alcoboles. Critica de los argumentos con que se pretende justificar la gravación. Opiniones favorables a la libre destilación, Barcelona, Establecimiento Tipográfico de Pedro Ortega.

Sierra Alonso, María (1992): La familia Ybarra, Sevilla, Muñoz Moya y Montraveta. VALDALISO, Jesús María (1990): «Política económica y grupos de presión: la acción colectiva de la Asociación de navieros de Bilbao 1900-1936», en Historia Social, núm. 7, primavera-verano, pp. 69-105.

VAREla OrTEga, José (1977): Los amigos politicos. Partidos, elecciones y caciquismo en la Restauración 1875-1900, Madrid, Alianza. 